\title{
PENGARUH KEBUGARAN JASMANI TERHADAP LAMA PERSALINAN KALA I DAN II PERSALINAN PADA IBU PRIMIGRAVIDADI BPM KOTA MEDAN TAHUN 2015
}

\author{
Sartini Bangun, Julietta Hutabarat, Lusiana Gultom \\ Jurusan Kebidanan Poltekkes Kemenkes Medan
}

\begin{abstract}
Physical fitness of pregnant women who are exercise actively have a better vascularization than those who passively. Physical exercise is a major factor in improving physical fitness, flow capacity of the heart, and obtain a high oxygen during labor (Varney and others 2007, Hamilton 1995, Bobak and others 2005), therefore team authors were interested in researching about physical fitness effectiveness for a long period time in first and second stage of labor in primigravida. Method : this type of research is a Quasi Experiment and Non-Equivalent Control Group, population total are 40 respondents (3rd trimester primigravida) measuring the level of physical fitness $\left(V O{ }_{\max }\right)$, period of $1^{\text {st }}$ stage, $2^{\text {nd }}$ stage and total period time of labor. Data analysis using $T$ test. Result : from 20 respondents of experimental group and 20 groups non-experiment obtained homogeneous data regarding physical fitness and psychological condition. The average time period of $1^{\text {st }}$ stage in experimental group are 387,75 minutes $(S d .43,54)$, the average time period of $2^{\text {nd }}$ stage are 27,75 minutes (Sd. 9,66). Total period of labor average 334,50 minutes (Sd. 44,35), while in nonexperimental group the period time of $1^{\text {st }}$ stage average 448,75 minutes (Sd. 41,64), $2^{\text {nd }}$ stage 40,00 minutes $(S d .8,27)$ and the average of total period are 478,75 minutes $(S d .82,64)$. $T$ test in the experimental group and non-experimental group obtained homogeneous data because $p$ value $(0,794)$ $>\alpha(0,005)$. Period time of $2^{\text {nd }}$ stage $p$ value $(0,602)>\alpha(0,005)$. The period time of labor not normal, analysist using Mann Whitney test obtained $p$ value $(0,00)<\alpha(0,005)$. Concluded that there is the influence of maternal physical fitness with period of $1^{\text {st }}$ and $2^{\text {nd }}$ stage of labor and suggested for all pregnant women improving physical fitness with physical exercise using a bicycle ergometer.
\end{abstract}

Keywords: Physical fitness, $1^{\text {st }}$ st and $2^{\text {nd }}$ stage of labor

\section{Pendahuluan}

Kasus kematian ibu lebih banyak terjadi akibat komplikasi persalinan, seperti perdarahan, persalinan macet/lama dan persalinan lama memberikan kontribusi terbesar yaitu 37\%. Banyak faktor yang menyebabkan persalinan lama antara lain faktor ibu meliputi paritas, his dan usia. Ibu primipara berisiko mengalami persalinan lama sebesar 2,06 kali dibandingkan ibu multipara (Wahyuningsih, 2009).

Persalinan lama dapat terjadi pada kala I dan kala II persalinan, dimana inersia uteri hipotonis merupakan salah satu faktor his yang dapat menyebabkan persalinan lama pada kala I. Kelainan kontraksi uterus ini disebabkan karena keletihan miometrium sehingga kontraksi uterus menjadi lemah, jarang serta tidak teratur. Keadaan ini dapat menyebabkan persalinan yang memanjang, dan apabila terjadi pada kala I fase aktif akan berimplikasi pada peningkatan infeksi intrapartum dan mortalitas perinatal. (Oxorn \& Forte, 2010)

Mengingat besarnya risiko komplikasi yang ditimbulkan oleh persalinan lama, dibutuhkan suatu cara yang lebih efisien dalam meningkatkan kontraksi uterus dengan melakukan olah raga. Secara fisiologis olahraga mampu meningkatkan kebugaran jasmani dan meningkatkan vaskularisasi darah sehingga dapat memperbaiki kontraksi otot. Beberapa penelitian juga menunjukkan bahwa kebugaran jasmani merupakan bagian essenial dari kesehatan ibu hamil, yang menghasilkan manfaat jangka panjang baik secara fisik maupun psikologis selama proses persalinan. (Guyton, 2008)

Kebugaran jasmani $\left(\mathrm{VO}_{2}\right.$ maks $)$ dipengaruhi oleh mekanisme kemampuan tubuh dalam menyediakan oksigen ke otot yang aktif bekerja, latihan fisik merupakan faktor utama yang mampu meningkatkan kapasitas aerobik, sehingga oksigen maksimal melebarkan pembuluh darah dan meningkatkan aliran balik vena dan curah jantung dan memperbesar hantaran oksigen dan nutrisi ke otot selama persalinan sehingga intensitas dan kekuatan otot menjadi lebih baik. (Depkes. 2005)

Penelitian Melzer dalam jurnal obstetgynecol, 2010 juga mengemukakan bahwa wanita hamil yang aktif melakukan aktifitas fisik moderat 30 menit/ hari mempunyai kebugaran jasmani yang lebih baik 
dibanding wanita yang tidak aktif. Lama persalinan kala II yang lebih cepat yaitu 88 menit pada wanita aktif dan 146 menit pada wanita yang tidak aktif. (Melzer dkk. 2010)

Populasi pada penelitian ini adalah semua ibu hamil primigravida dengan usia kehamilan trisemester III yang melakukan pemeriksaan kehamilan di Bidan Praktek Mandiri Kota Medan. Sampel penelitian diambil dengan teknik purposive sampling, dengan kriteria inklusi umur ibu 20-35 tahun, Body Mass Indeks sebelum hamil normal (18,5-24,9 kg/m2), penambahan berat badan selama hamil normal (11,5-16 $\mathrm{kg}$ ), Denyut jantung janin normal (120-160 kali/menit) dan Tinggi badan > $145 \mathrm{~cm}$, usia kehamilan 36- 40 minggu, hasil koesioner tentang aktifitas fisik kategori ringan dan data psikologis kategori tingkat kecemasan rendah.

\section{Metode Penelitian}

Jenis penelitian yang digunakan adalah Quasi Eksperimen, dengan rancangan penelitian NonEquivalent Control Group dimana terdapat kelompok eksperimen yaitu kelompok yang diberi perlakuan kebugaran jasmani dan yang tidak diberi perlakuansebagai kelompok non eksperimen. Notoadmodjo A. (2012)

\section{Analisis Data}

Uji normalitas data menggunakan Shapiro-Wilk, karena data pada kelompok eksperimen dan kelompok non eksperimen berdistribusi normal (Data Kala I dan Kala II), sehingga digunakan uji T- Test yaitu independen sampel T-Test, sedangkan data untuk total lama persalinan menggunakan uji Mann Whitney karena ditemukan data salah satu kelompok tidak berdistribusi normal. Notoadmodjo A. (2012)

\section{Hasil}

Subjek yang memenuhi kriteria inklusi sebanyak 40 orang, 20 orang pada kelompok eksperimen dan 20 orang pada kelompok non eksperimen. Pada semua subjek (criteria inkusi) diberikan kuesioner tentang aktivitas fisik dimana hasil pekerjaan utama pada kategori pekerjaan ringan, dan kuesioner psikologis dengan hasil kategori tingkat kecemasan rendah. Selanjutnya pada kelompok eksperimen diberikan perlakuan latihan naik sepeda ergometer untuk mencapai kebugaran jasmani.

Melalui latihan minimal empat kali dengan durasi 6-12 menit, untuk mencapai dengut nadi maksimal (DNM) baru dikatakan bugar dan menjadi subjek penelitian, pada ibu primigravida dengan usia kehamilan 36-40 minggu. Hasil penelitian selengkapnya dapat dilihat pada tabel dibawah ini:
Tabel 1. Uji Normalitas Data Lama Kala I, Lama Kala II dan Total Lama Persalinan

\begin{tabular}{cccc}
\hline No & Variabel & \multicolumn{2}{c}{ Shapiro- Wilknilai p } \\
\cline { 3 - 4 } & Eksperimen & $\begin{array}{c}\text { Non } \\
\text { Eksperimen }\end{array}$ \\
\hline $\mathbf{1}$ & Lama KalaI & 0,136 & 0,208 \\
$\mathbf{2}$ & Lama Kala II & 0,069 & 0,325 \\
$\mathbf{3}$ & Total Lama & 0,396 & 0,00 \\
& Persalinan & & \\
\hline
\end{tabular}

Pada Tabel 1 diatas berdasarkan uji normalitas diperoleh hasil untuk variable Lama Kala I dan Kala I inilai $\mathrm{p}>\alpha(0,005)$ baik pada kelompok eksperimen maupun kelompok non eksperimen, sehingga dapat disimpulkan bahwa data berdistribusi normal. analisis dengan uji $\mathrm{T}$ Test yaitui ndependen sampel T-Test. Sedangkan untuk variable total lama persalinan pada kelompok non eksperimen data tidak berdistribusi normal dimana nilai $\mathrm{p}(0,00)<\alpha(0,005)$ sehingga analisis dilakukan dengan menggunakan uji Mann Whitney.

\section{Uji T-Test}

Untuk mengetahui pengaruh kebugaran jasmani terhadap lama kala I dan kala II persalinan maka dilakukan uji T-Test seperti yang terlihat pada tabel dibawah ini :

Tabel 2. Pengaruh Kebugaran Jasmani terhadap Kala I dan Kala II Persalinan

\begin{tabular}{|c|c|c|c|c|c|}
\hline \multirow[b]{2}{*}{ Eksperimen } & \multirow[b]{2}{*}{ Mean } & \multirow[b]{2}{*}{ Std.Deviation } & \multicolumn{2}{|c|}{ Levenen's Test } & \multirow{2}{*}{$\begin{array}{l}\text { t-Test } \\
\text { Sig.(2- } \\
\text { tailed }\end{array}$} \\
\hline & & & F & Sig & \\
\hline \multicolumn{6}{|l|}{ Kala I } \\
\hline Eksperimen & 307,75 & 43,543 & 0,069 & 0,794 & 0,000 \\
\hline Non & 448,75 & 41,640 & & & \\
\hline \multicolumn{6}{|l|}{ Eksperimen } \\
\hline Kala II & 27,75 & 9,662 & 0,277 & 0,602 & 0,000 \\
\hline $\begin{array}{l}\text { Eksperimen } \\
\text { Non }\end{array}$ & 40,80 & 8,272 & & & \\
\hline Eksperimen & & & & & \\
\hline
\end{tabular}

PadaTabel 2 diatas dapat disimpulkan ada pengaruh yang signifikan antara kebugaran jasmani dengan lama Kala I dan Kala II persalinan dimana dari hasil uji T-Test diperoleh nilai $p(0,00)<\alpha(0,005)$ dan berdasarkan Levenen's Test diperoleh hasil nilai $\mathrm{p}$ $(0,794)>\alpha \quad(0,005)$ pada Kala I dan nilai $p(0,602)>\alpha$ $(0,005)$ pada Kala II. Hal ini berarti diperoleh hasil asumsi varians sama atau data relative homogeny pada Kala I dan Kala II persalinan baik pada kelompok eksperimen dan non eksperimen.

\section{Hasil Uji Mann-Whitney U-Test}

Untuk mengetahui pengaruh kebugaran jasmani terhadap total lama persalinan maka dilakukan MannWhitney U-Test seperti yang terlihat pada tabel dibawah ini : 
Tabel 3. Pengaruh Kebugaran Jasmani Terhadap Total Lama Persalinan

\begin{tabular}{cccl}
\hline \multirow{2}{*}{ Perlakuan } & \multirow{2}{*}{ Mean } & Std. & Mann-Whitney \\
& Deviation & U-Test \\
\hline
\end{tabular}

Total Lama

Persalinan

Eksperimen

$$
334,50
$$

Non

478,75

82,635

Eksperimen

Pada tabel 3 diketahui dari hasil uji Mann Whitney diperoleh nilai $p(0,00)<\alpha(0,005)$, artinya ada pengaruh kebugaran jasmani terhadap total lama persalinan.

\section{Pembahasan}

1. Pengaruh Kebugaran Jasmani Terhadap Lama Persalinan Kala I Ibu Primigravida

Pada kelompok eksperimen yang dilakukan tes kebugaran jasmani $\left(\mathrm{VO}_{2 \text { maks }}\right)$ pada umur kehamilan 36-40 minggu ibu primigravida, setelah dilakukan latihan kebugaran jasmani dengan frekuensi $4-8$ kali dan durasi $6-12$ menit, diperoleh rata-rata lama kala I : 387,75 menit (6,45 jam) dan sedangkan pada kelompok non eksperimen rata-rata 448,75 menit (7,48 jam). Dari hasil ini dapat dikatakan bahwa tingkat kebugaran jasmani akan memperpendek lama waktu proses persalinan, dengan kata lain bila tercapai kebugaran jasmani maksimal maka rasa nyeri yang berkaitan dengan lama waktu persalinan akan berkurang sebanyak 1 jam lebih 20 menit. Penelitian ini sejalan dengan teori Friedman rata-rata durasi kala I fase aktif pada nulipara 6 jam dengan nilai maksimum 11,7 jam. Secara rata-rata dan nilai minimun lama persalinan kala I fase aktif pada subjek penelitian sama nilai menurut Friedman. Penelitian berbeda Roberg RA dkk, 2003 meneliti 238 ibu bersalin usia 16-38 tahun di Nigeria dengan metode observasional prospektif, hasilnya rata-rata lama persalinan pda nulipara 11,23 jam.

\section{Pengaruh Kebugaran Jasmani Terhadap Lama Persalinan Kala II Ibu Primigravida}

Setelah dilakukan latihan kebugaran jasmani $\left(\mathrm{VO}_{2 \text { maks }}\right)$ pada umur kehamilan 30-40 minggu ibu primigravida, dengan frekuensi $4-8$ kali dengan durasi 20 - 45 menit dengan intensitas $85 \%-95 \%$ dapat diperoleh Lama kala II pada kelompoke ksperimen rata-rata 27,75 menit dan kelompok non eksperimen rata-rata 40,00 menit. Terjadi perbedaan waktu dimana pada kelompok ekperimen waktunya lebih pendek dengan selisih waktu 12,25 menit. Waktu ini cukup penting dalam mengantisipasi terjadinya perdarahan yang juga merupakan salah satu penyebab utama kematian ibu. Sementara menurut Friedman lama kala II persalinan rata-rata 46 menit. Kala II pada nulipara dibatasi sampai 2 jam. Penelitian ini lama kala II lebih pendek dari teori Friedman, hal ini berhubungan dengan kekuatan aktivitas otot rahim untuk berkontraksi. Kardel dkk. ${ }^{14}$ melakukan penelitian observasional pada ibu nulipara usia kehamilan 35-37 mg untuk melihat hubungan antara kebugaran jasmani $\left(\mathrm{VO}_{2 \mathrm{maks}}\right)$ dengan lama persalinan. Hasil deskriptifnya rata-rata nilai $\mathrm{VO}_{2 \text { maks }} 2,1 \mathrm{~L} /$ menit, lama persalinan kala I yang dinilai dari pembukaan $3 \mathrm{~cm}$ sampai pembukaan lengkap, rata-rata durasinya; 569 menit, rata-rata lama kala II 45 menit, dan total lama persalinan rata-rata 583 menit. Penelitian ini berbeda karena kriteria sampel yang berbeda besar sampel dan usia kehamilan, Hasil penelitian Yoong dkk yang membandingkan lama persalinan antara etnis Kosovo dengan etnis kulit putih (Caucasian) di London menunjukkan bahwa lama persalinan pada etnis Kosovo lebih pendek yaitu 5,52 jam, sedangkan pada etnis Caucasian 7,13 jam $(\mathrm{P}=0,015)$.

\section{Pengaruh Kebugaran Jasmani Terhadap Total Lama Persalinan Ibu Primigravida}

Setelah dilakukan latihan kebugaran jasmani ( $\mathrm{VO}_{2 \text { maks }}$ ) pada ibu primigravida umur kehamilan 36-40 minggu, dengan frekuensi $4-8$ kali dan durasi $20-$ 45 menit dengan intensitas $85 \%-95 \%$ dapat diperoleh total lama persalinan pada kelompok eksperimen ratarata 334,50 menit $(5,57$ jam $)$ dan kelompok non eksperimen rata-rata 478,75 menit $(7,79$ jam), maka dapat disimpulkan total waktu pada ibu primigravida yang melakukan latihan kebugaran jasmani jauh lebih sedikit bila dibandingkan dengan total waktu ibu primigravida yang tidak melakukan latihan kebugaran jasmani, dengan selisih lama waktu 2 jam 22 menit. Dengan kata lain waktu ini sangat berkaitan dengan tingkat penurunan kecemasan ibu dan keluarga. Penelitian ini didukung oleh hasil beberapa studi lain yang menyatakan bahwa wanita yang mempunyai nilai kebugaran jasmani $\left(\mathrm{VO}_{2 \text { maks }}\right)$ yang lebih tinggi juga. mempunyai kondisi kardiovaskuler yang lebih baik dibandingkan dengan wanita yang tidak aktif. (Masdin, 2010). Hasil lain yang sejalan dengan penelitian ini adalah penelitian Homs dkk. yang membandingkan waktu persalinan wanita aktif dengan wanita yang tidak aktif, lama kala I pada wanita aktif 11,5 jam dan pada wanita tidak aktif 12,6 jam. Total lama persalinan pada wanita aktif 13,4 jam dan pada wanita tidak aktif 14,6 jam.

\section{Kesimpulan dan Saran}

Disimpulkan bahwa ada pengaruh kebugaran jasmani ibu hamil dengan lama kala I dan Kala II persalinan dan disarankan untuksemua ibu hamil meningkatkan kebugaran jasmani salah satu dengan latihan fisik (speda ergometri).

\section{Daftar Pustaka}

Dep Kes RI: 2005 Direktorat Jenderal Bina Kesehatan Masyarakat. Petunjuk tehnis pengukuran kebutuhan jasmani. Jakarta

Guyton AC, Hall FE. 2008 Buku Ajar Fisiologi Kedokteran. Edisi ke-11. Jakarta: EGC. 
Homs, Tavares Jde S, Melo AS, Amorim MMR, Barros Vde O, Benicio MH, Takito MY, dkk. 2009 Association between maternal physical activity, gestational weight gain and birth weight in a cohort of 118 pregnant women in Campina Grande, Northeast of Brazil. Rev Assoc Med Bras.;55(3):335-41.

Kardel KR, Johansen B, Voldner M, Iversen PO, Henriksen Y. 2009 Association between aerobic fitness in late pregnancy and duration of labor in nulliparous women. Acta Obstet Gynecol Scand.; 88(8):148-52.

Masdin. 2010 Senam dan kegiatan fisik lainnya untuk mencegah preeklamsia dan komplikasi-komplikasi lain (sebuah review) Info Jurnal; 9 Februari ( diunduk 16 Juni 2014). Tersedia dari URL : http://infojurnal.blogspot.com/2010/02/senam dankegiatan -fisik -lainnya- untuk-html.

Melzer K,Schutz Y, soehnchen N. Othenin-Girard V, Martinez de Tejada B, 2010 Iron d,dd. Effec of recommended levels of physical activity on pregnancy outcomes. AM J Obstet Gynecol.; 201 (3): 266.el-ed.

Notoadmodjo A. (2012) Metodologi Penelitian. Jakatra; Erlangga.

Oxorn H, Forte W. 2010 Ilmu Kebidanan: Patologi dan fisiologi persalinan. Yogyakarta; Yayasan Essentia Medica.

Roberg RA, Kateyian SJ. 2003 Fundamentals of exercise physiology for fitness, performance, and health. Second edition. New York: Mc Graw Hill.

Wahyuningsih MD. 2009 Insidensi partus lama pada primipara dan multipara di RSUD Dr. Moewardi Surakarta [Skripsi]. Surakarta: Universitas Muhammadiyah.

Yoong W, Wagley A, Fong C, Chukwuma C, Nauta M. 2004 Obsetetri performance of ethnic Kosovo Albanian asylum seekers in London: a case-control study. J Obstet Gynecol.;24(5):510-2. 